\title{
Mucosal ablation using photodynamic therapy for the treatment of dysplasia: an experimental study in the normal rat stomach
}

\author{
C S Loh, A J MacRobert, G Buonaccorsi, N Krasner, S G Bown
}

\begin{abstract}
Surgery is the only effective treatment for dysplasia in the gastrointestinal tract with considerable associated morbidity and mortality and is difficult to justify without confirmed malignancy. Photodynamic therapy (PDT) produces localised necrosis, which can be limited to the mucosa. This study examined the mechanical properties of the normal rat stomach after PDT. The aim of this study was to measure the bursting pressure of PDT lesions in the stomach and to assess gastric emptying after producing circumferential mucosal necrosis at the pylorus by PDT. Two photosensitising agents were used 5-aminolaevulinic acid (ALA), and aluminium disulphonated phthalocyanine $\left(\mathrm{AlS}_{\mathbf{2}} \mathrm{Pc}\right)$. Normal rats were sensitised and PDT lesions created in the stomach with red light. The bursting pressure was measured and compared with that in thermal control lesions. In further experiments, circumferential mucosal necrosis was produced at the pylorus, and animals observed for subsequent eating and weight gain. It was found that gastric bursting pressure was reduced after thermal injury, but not at any time after PDT (with $\mathrm{AlS}_{2} \mathbf{P c}$, but not ALA, adhesive omental reinforcement was required to maintain the gastric wall strength at one week). For the pyloric lesions, gastric emptying was permanently impaired using $\mathrm{AlS}_{2}$ Pc, but with low dose ALA (20 $\mathrm{mg} / \mathrm{kg}$ ) had returned to normal by three days. With ALA, but not $\mathrm{AlS}_{2} \mathrm{Pc}$, necrosis could be limited to the mucosa. In conclusion, using ALA, selective ablation of the gastric mucosa is possible, which does not reduce the strength of the stomach and only temporarily delays gastric emptying. PDT is a promising technique for the circumferential ablation of dysplastic mucosa.
\end{abstract}

(Gut 1996; 38: 71-78)

Keywords: photochemotherapy, photodynamic therapy, mucosa, stomach, aminolaevulinic acid, phthalocyanine, dysplasia.

The importance of dysplasia as a risk factor for the subsequent development of frank malignancy in many parts of the gastrointestinal tract is well established. ${ }^{1-5}$ Dysplasia does not necessarily progress relentlessly to carcinomas and indeed, spontaneous regression is occasionally seen. ${ }^{267}$ The risk of carcinogenesis is significant in the presence of high grade dysplasia. 368 The treatment of gastrointestinal dysplasia is controversial. In most centres, regular endoscopic reviews and biopsies are carried out, and surgery is only carried out when the dysplasia becomes severe or carcinoma develops. ${ }^{39-11}$ Excisional surgery is a major procedure. For dysplastic Barrett's oesophagus, this would entail segmental oesophagectomy, which carries a considerable morbidity. 811 For dysplasia in a gastric remnant after partial gastrectomy, the only option is total gastrectomy in view of its multicentricity ${ }^{12}$ and the complications of this are well known. Photodynamic therapy (PDT) has the potential to destroy dysplastic mucosa over an extended area or small localised carcinomas without the need for surgery. ${ }^{13}$ PDT is a technique for producing localised tissue necrosis with light following prior systemic administration of a photosensitising drug. This effect has some degree of selectivity between tumour and normal tissue although the selectivity is often difficult to exploit. ${ }^{14}$ It is now becoming clear, however, that with careful choice of treatment parameters, it is possible to get selectivity between different layers of normal tissue. In the bladder, it has been shown experimentally in normal rats that the entire mucosa can be destroyed without any damage to the underlying muscle and with only temporary impairment of bladder function. ${ }^{15}$ If the same can be achieved in the gastrointestinal tract, producing circumferential mucosal necrosis without unacceptable damage to the underlying muscle, then PDT might be a valuable approach to treating dysplasia in Barrett's oesophagus or a gastric remnant.

Haematoporphyrin derivative $(\mathrm{HpD})$ and its commercial preparation, Photofrin, are the most widely studied photosensitisers although they suffer from several important disadvantages. They are complex mixtures of porphyrins, ${ }^{16} 17$ which are unstable upon prolonged storage at room temperature. ${ }^{18}$ In clinical use, the main problem is prolonged skin photosensitivity, which may last several weeks. ${ }^{19}$

Aluminium sulphonated phthalocyanine (AlSPc) is a new water soluble photosensitiser with better photochemical ${ }^{20}$ and pharmacokinetic properties ${ }^{21}$ than haematoporphyrin derivative and has been extensively studied in this centre. ${ }^{14}$ 20-23 Barr showed that the microscopic distribution of AlSPc (a mixture of mono- di, tri, and tetrasulphonated derivatives), like Photofrin, is mainly in the vascular stroma of both normal and tumour tissue. ${ }^{21} 22$ 


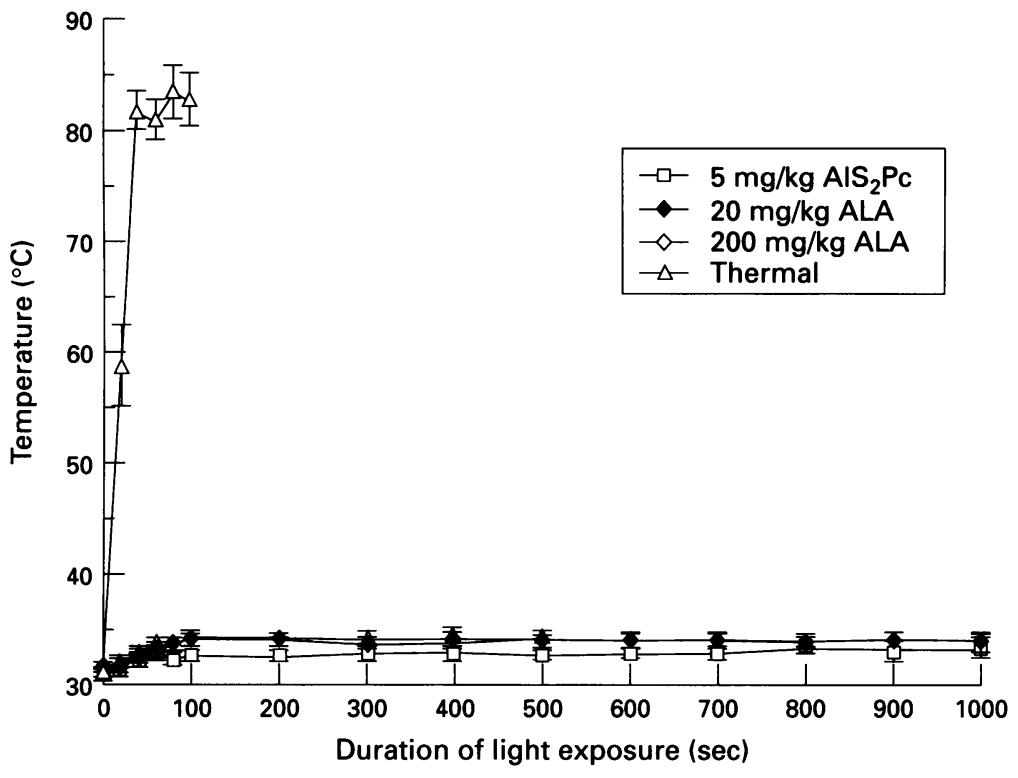

Figure 1: Mean temperature $\left({ }^{\circ} \mathrm{C}\right)$ on the serosal aspect of the normal glandular stomach at the point of the laser fibre tip. Each value represents the mean (with $95 \%$ confidence intervals) in 12 animals. of mucosal epithelial cells with minimal new collagen deposition. Selective mucosal necrosis could not be achieved with $\mathrm{AlS}_{2} \mathrm{Pc}$, whatever the dose.

Recently, PDT using the photosensitiser Photofrin has been used to treat dysplastic mucosa in Barrett's oesophagus. ${ }^{13}$ The treated areas healed without oesophageal perforation and with more normal mucosa than present originally, although mild strictures did develop that required dilatation. In this paper, we report the result of an experimental study in the normal rat stomach with $\mathrm{AlS}_{2} \mathrm{Pc}$ and ALA to assess their potential as photosensitising drugs for producing mucosal ablation with PDT with safe healing by regeneration and without the risk of perforation or stenosis.

\section{Methods}

These experiments were divided into two groups - those to assess the bursting pressure of treated areas and those to assess the risk of stenosis. Single lesions for the bursting studies were made in the glandular part of the rat stomach well away from the pylorus and the limiting line with the non-glandular part of the stomach (the forestomach). To assess the risk of stenosis, it was necessary to produce circumferential mucosal necrosis, and this was done most conveniently at the pylorus. full thickness necrosis and subsequent healing was associated with formation of scar tissue bridging the full thickness defect. This was more severe damage than $\mathrm{Barr}^{22}$ had reported in the colon, but the mechanical strength of the stomach after PDT was not tested.

5-Aminolaevulinic acid (ALA) in itself is not a photosensitiser. It is a natural porphyrin precursor and its synthesis by living cells is the first committed step, which eventually leads to haem formation. In this biosynthesis pathway, the rate limiting step is at the formation of ALA, which is controlled by regulatory feedback inhibition. ${ }^{25}{ }^{26}$ By giving a large quantity of exogenous ALA in both in vitro systems as well as whole animals, it has been shown that the natural regulatory mechanism can be bypassed and as a result, porphyrin intermediates of the biosynthesis pathway, particularly protoporphyrin IX (PpIX), accumulate. ${ }^{27} 28$ This accumulation is transient as PpIX is later converted by ferrochelatase to the nonphotoactive haem. PpIX is a potent photosensitiser and its transient presence in excessive quantity can be exploited for PDT. Loh et $a l^{24}$ have shown that after intravenous or oral administration of ALA, PpIX build up in the stomach as measured by fluorescence microscopy is predominantly in the mucosal layer where the concentrations can be at least 10 times those in the muscularis propria. Light exposure following $200 \mathrm{mg} / \mathrm{kg}$ of intravenous ALA resulted in necrosis of the epithelial as well as smooth muscle cells but the tissue framework was preserved. Healing was associated with considerable new collagen deposition. When the dose of ALA was reduced to 20 $\mathrm{mg} / \mathrm{kg}$ intravenously, the PDT effect was confined to the mucosa resulting in selective mucosal ablation. Healing was by regeneration

\section{Photosensitisers}

$\mathrm{AlS}_{2} \mathrm{Pc}$ was purified and analysed using high performance liquid chromatography (HPLC) at the Department of Chemistry, Imperial College of Science Technology and Medicine, London. The disulphonated fraction was separated from a mixture prepared by the oleum sulphonation of aluminium phthalocyanine chloride, using reverse phase liquid chromatography. This fraction contained a range of disulphonated isomers dominated by the most hydrophobic component, which comprised $60 \pm 5 \%$ of its integrated HPLC. ${ }^{29}$ The photosensitiser was made up in 0.1 molar sodium hydroxide and phosphate buffered saline and given intravenously through the tail vein. ALA was obtained as a hydrochloride (formula weight $=167 \cdot 6$ ) in $98 \%$ pure powder form from Sigma Chemical Company (Poole, UK). It was dissolved in phosphate buffered saline for intravenous administration.

\section{Animals}

All studies were performed on young adult female Wistar rats supplied by the Imperial Cancer Research Fund. Their mean (SD) weight at the time of study was 157 (12) g. Injections of photosensitisers were carried out under intramuscular Hypnorm (fentanyl and fluanisone) anaesthesia. The concentration of photosensitiser was adjusted to maintain the volume of injection between $0 \cdot 3-0.5$ $\mathrm{ml}$ to ensure accuracy. Photodynamic therapy was carried out during laparotomy under intramuscular Hypnorm and diazepam anaesthesia. 


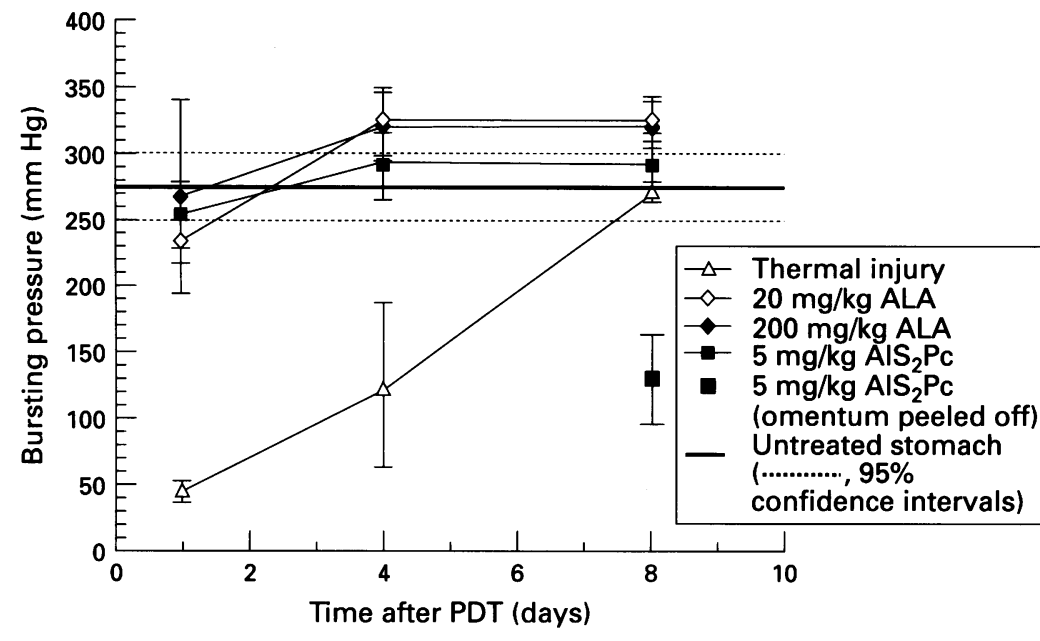

Figure 2: Bursting pressures of stomachs at one, four, and eight days after thermal damage and PDT with $20 \mathrm{mg} / \mathrm{kg}$ of $A L A$, $200 \mathrm{mg} / \mathrm{kg}$ of $A L A$, and 5 $\mathrm{mg} / \mathrm{kg}$ of $\mathrm{AlS} \mathrm{S}_{2} \mathrm{Pc}$. Each value represents the mean bursting pressure (with 95\% confidence intervals) measured in four animals.

\section{Bursting pressure study}

Animals were divided into four groups of 12 animals each. The first group was sensitised intravenously with $5 \mathrm{mg} / \mathrm{kg}$ of $\mathrm{AlS}_{2} \mathrm{Pc}$. The second group received $20 \mathrm{mg} / \mathrm{kg}$ ALA intravenously and the third group $200 \mathrm{mg} / \mathrm{kg}$ ALA intravenously. The final group was given no sensitiser, but the same quantity of light was delivered at a higher power to produce thermal lesions. In an earlier study, ${ }^{24}$ we had found no differential $\mathrm{AlS}_{2} \mathrm{Pc}$ distribution between the gastric mucosa and muscularis at any time after administration. Because of this, only one dose was used in our $\mathrm{AlS}_{2} \mathrm{Pc}$ group, which was known to produce consistent panmural damage on light exposure. The light source was a pulsed $(12 \mathrm{kHz})$ copper vapour pumped dye laser (Oxford Lasers). The beam was delivered by a $200 \mu \mathrm{m}$ fibre threaded into the stomach through a small bore plastic canula introduced orally down the oesophagus and held just in contact with the mucosa of the glandular stomach at a point $1 \mathrm{~cm}$ distal to the limiting line along the greater curve. The fibre was maintained at approximately $90^{\circ}$ to the mucosal surface. The rest of the abdominal viscera were shielded from forward light scatter by interposition of a piece of opaque paper. Only one point was treated per animal. Power

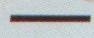

Figure 3: Light micrograph of a haematoxylin van Gieson stained section of gastric wall 24 hours after thermal injury. The bursting experiment had caused a perforation of the treated area represented by the charred necrotic mucosa (muc) herniating through the weakened muscularis (mus). Scale: the bar in the bottom right corner represents $100 \mu \mathrm{m}$. output from the fibre tip was set to $50 \mathrm{~mW}$ with a total irradiation time of 1000 seconds giving a total energy delivery of $50 \mathrm{~J}$ per animal. In the $\mathrm{AlS}_{2} \mathrm{Pc}$ group, the output was tuned to $675 \mathrm{~nm}$ (peak absorption for $\mathrm{AlS}_{2} \mathrm{Pc}$ ) and light exposure was effected two hours after administration of photosensitiser, when peak tissue $\mathrm{AlS}_{2} \mathrm{Pc}$ concentration is achieved. ${ }^{24}$ In the ALA groups, the laser was tuned to $630 \mathrm{~nm}$ and the same power and energy was used. Each animal was photoirradiated at the time of peak tissue fluorescence as determined from a previous study ${ }^{24}$ - that is, one hour after 20 $\mathrm{mg} / \mathrm{kg}$ of ALA or three hours after $200 \mathrm{mg} / \mathrm{kg}$ ALA. Thermal damage was deliberately produced in the final group of animals that received no photosensitiser. They were photoirradiated as above at $630 \mathrm{~nm}$ but using $500 \mathrm{~mW}$ for only 100 seconds giving a similar energy of $50 \mathrm{~J}$ per animal. Temperature changes during photoirradiation were measured with a microthermocouple (Jenway 7900 S) placed on the serosa at the point of contact of the laser fibre with the mucosa.

The bursting strength of the stomach at various times after PDT or thermal lesions were produced was measured by gradual gaseous distension under a bath of physiological saline. ${ }^{30}$ Four animals were used for each group at each time point. After an overnight fast to ensure an empty stomach, animals were killed at one day, four days, and eight days after treatment. The abdomen was opened and the peritoneal cavity and stomach inspected macroscopically before the stomach was carefully excised with a short length of attached duodenum and oesophagus and prepared for the bursting study. Bursting pressure was measured by an inline pressure transducer connected to an oscillograph (M10-120A, Micro Movement). The pressure transducer was calibrated against a mercury column before each measurement. The duodenal end of the stomach was securely fastened to a cannula, which was then connected to the pressure line. Oxygen from a piped source was delivered through a flow meter at a rate of $100 \mathrm{ml} / \mathrm{min}$ to distend the stomach. Initial studies on control untreated stomachs with proximal ligation on the oesophagus showed the weakest point to be near the gastrooesophageal junction in the forestomach of which there is no human equivalent, so all measurements on study stomachs were carried out with the forestomach excluded by means of a clamp placed along the limiting line (the squamocolumnar junction of the stomach). Bursting pressures were recorded as peak distension pressures achieved before the precipitous drop after perforation. Omental adhesion was evident on the serosal aspect of the treated area of the stomach eight days after PDT (but not after one or four days) in the phthalocyanine group but not in the two ALA groups. To assess the part played by this omental adhesion in the maintenance of mechanical strength in this group, a further four animals were treated using the same parameters but the omental adhesion was peeled off just before measuring the bursting pressure eight days after PDT. 


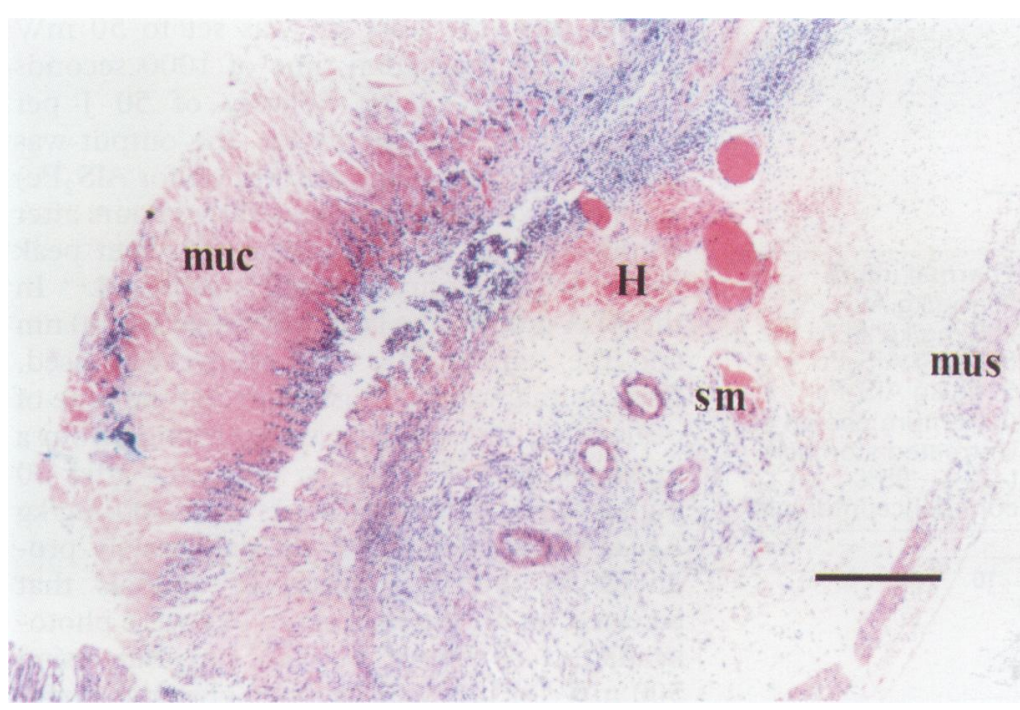

Figure 4: Light micrograph of a haematoxylin and eosin stained section of gastric wall 24 hours after PDT with $5 \mathrm{mg} / \mathrm{kg} \mathrm{AlS} \mathrm{Pc}_{2}$ showing necrosis of the mucosa (muc) and muscularis (mus). The submucosa (sm) was oedematous with areas of interstitial haemorrhage $(H)$. Scale: the bar in the bottom right corner represents $100 \mu \mathrm{m}$.

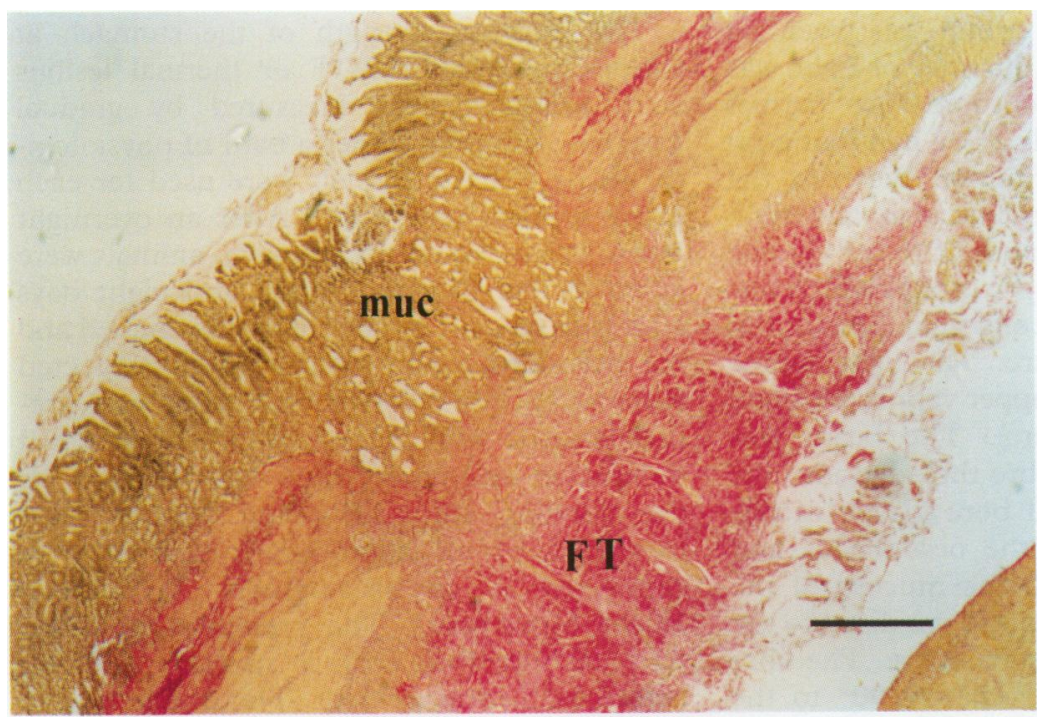

Figure 5: Light micrograph of a haematoxylin van Gieson stained section of gastric wall six weeks after PDT with $5 \mathrm{mg} / \mathrm{kg}$ AlS $\mathrm{S}_{2} \mathrm{Pc}$ showing complete re-epithelialisation (muc). The omental tissue had organised into dense fibrotic tissue (FT), which stained strongly pink for collagen. Scale: the bar in the bottom right cormer represents $100 \mu \mathrm{m}$.

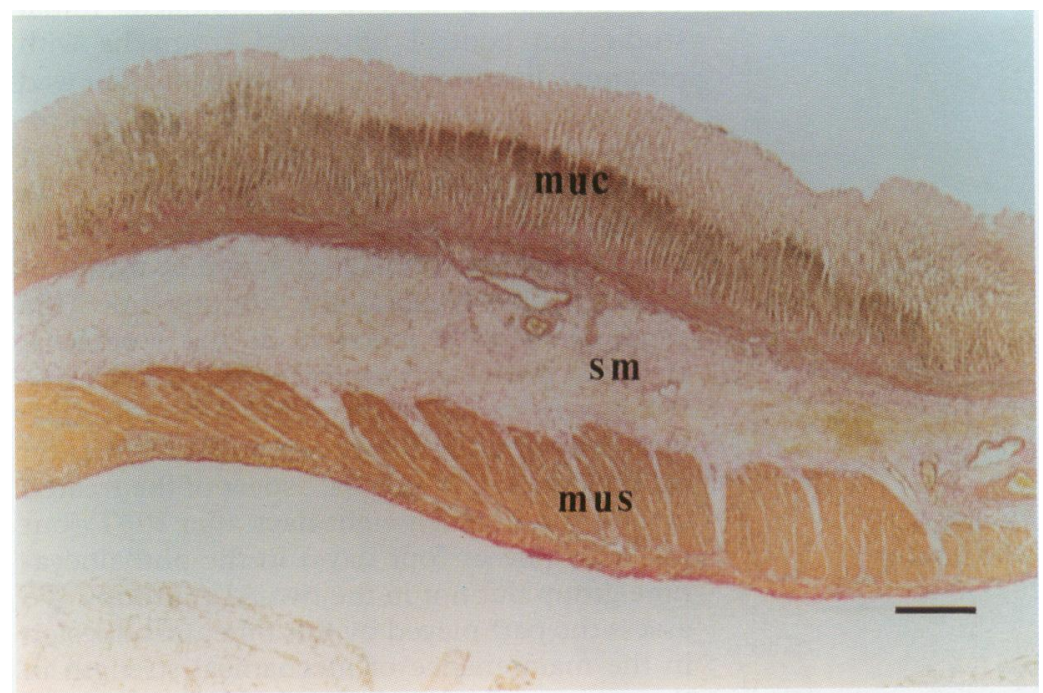

Figure 6: Light micrograph of a haematoxylin van Gieson stained section of gastric wall 24 hours after PDT with $20 \mathrm{mg} / \mathrm{kg}$ ALA showing mucosal necrosis (muc), submucosal oedemo (sm), and intact muscularis (mus). Scale: the bar in the bottom right corner represents $100 \mu \mathrm{m}$.
Immediately after the stomach had burst, it was opened and noted whether the stomach had burst through the lesion or in a normal area. The photodynamic or thermal lesion was then excised, fixed with formalin, and the specimen prepared for paraffin wax sections. Two $4 \mu \mathrm{m}$ thick serial sections were cut using a microtome (Reichert-Jung). One section was stained with haematoxylin and eosin and the other with haematoxylin van Gieson stains. These sections were then studied under conventional light microscopy. Further specimens were obtained from additional animals two and six weeks after PDT using the same treatment parameters for histological analysis although bursting studies were not done at these time intervals.

\section{Stenosis study}

This study was undertaken to assess the mechanical effect and healing of a larger area of necrosis that extended circumferentially around the stomach. The pylorus was the most suitable site at which to produce these lesions as any obstruction at this site would be manifested by gastric distension. All animals were fasted overnight to ensure an empty stomach. They were divided into three groups of 18 animals each. One group received no photosensitiser (control group). The other two groups were given intravenously $2.5 \mathrm{mg} / \mathrm{kg} \mathrm{AlS}{ }_{2} \mathrm{Pc}$ and $20 \mathrm{mg} / \mathrm{kg}$ ALA respectively. The lower dose of $2.5 \mathrm{mg} / \mathrm{kg}$ of $\mathrm{AlS}_{2}$ Pc was used here because it was found in a preliminary study that $5 \mathrm{mg} / \mathrm{kg}$ of $\mathrm{AlS}_{2} \mathrm{Pc}$ led to too much damage of surrounding organs from forward light scatter from within the stomach. Light exposure was again matched to the time of peak tissue fluorescence of the respective photosensitisers. At laparotomy, a $400 \mu \mathrm{m}$ freshly cleaved fibre was threaded through the greater curvature into the stomach toward the pylorus and held about 1 $\mathrm{cm}$ from the pyloric canal. The fibre was adjusted until the diverging beam of light covered the entire pylorus as assessed by the pattern of forward scatter seen outside the stomach. A laser power of $100 \mathrm{~mW}(\lambda=675$ $\mathrm{nm}$ ) was used over a time of 1000 seconds for $\mathrm{AlS}_{2} \mathrm{Pc}$. In the ALA group, the laser was tuned to $630 \mathrm{~nm}$ and the same power was used although the exposure time was prolonged to 2000 seconds to produce consistent circumferential lesions. The same light parameters were used on control animals $(630 \mathrm{~nm}, 100$ $\mathrm{mW} \times 2000$ seconds). The area irradiated in each animal was estimated to be approximately $1 \mathrm{~cm}^{2}$ giving an estimated power density of 100 $\mathrm{mW} / \mathrm{cm}^{2}$ and energy density of 100 and 200 $\mathrm{J} / \mathrm{cm}^{2}$ respectively. All animals were weighed prior to study and at one day, two weeks, four weeks, and six weeks as a simple measure of their ability to maintain their nutrition. Animals from the ALA and control groups were killed in batches of three at day 1,2 , and 3 to study the acute effect of PDT, at one and two weeks to study early healing and six weeks to study late healing as a previous study had shown complete re-epithelialisation by six weeks (unpublished data). Animals from the phthalocyanine 


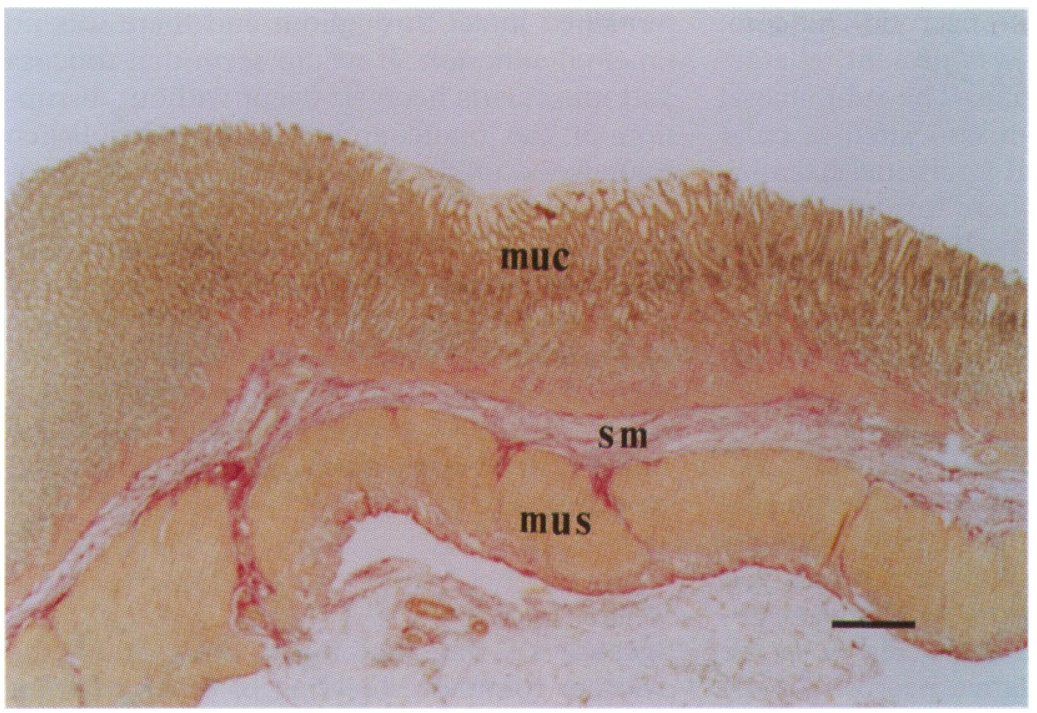

Figure 7: Light micrograph of a haematoxylin van gastric wall six weeks after $P D T$ with $20 \mathrm{mg} / \mathrm{kg} A L A$ showing regenerated mucosa (muc) and normal submucosa (sm) and muscularis (mus) propria. Scale: the bar in the bottom right corner represents $100 \mu \mathrm{m}$.

group were similarly killed for study in batches of three at day 1, 2, and 3 and at one week after PDT. All remaining animals from this group, however, had to be killed at two weeks after PDT because of their frail general condition and severe weight loss. A laparotomy was carried out as soon as the animal was killed to inspect the state of gastric distension. The Gieson stained section of pylorus was then excised and prepared for conventional light microscopy.

\section{Results}

\section{Temperature changes}

Figure 1 shows the temperature changes during photoirradiation in all three groups of animals. The temperature rise recorded during PDT was small and we were confident that no thermal effects were produced. When the stomach was irradiated at $500 \mathrm{~mW}$, the temperature on the serosa opposite the optic fibre rose to a mean peak of $84^{\circ} \mathrm{C}$.

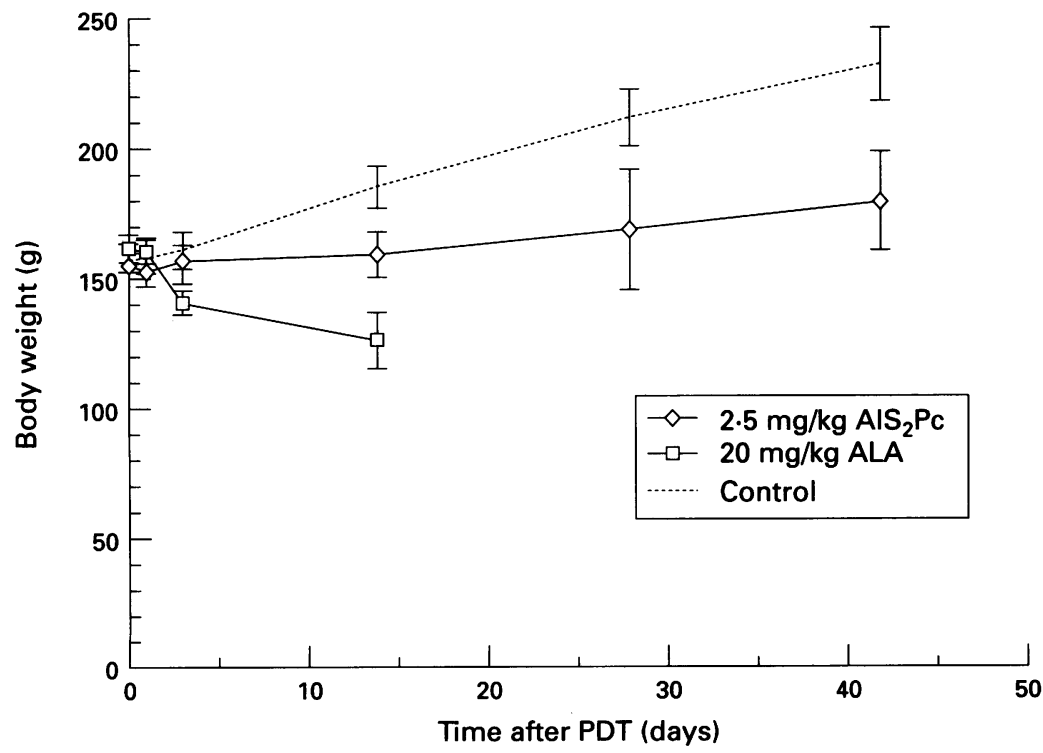

Figure 8: Weight changes after circumferential photodynamic damage of the pylorus using $2.5 \mathrm{mg} / \mathrm{kg}$ of $A l S_{2} P c$ and $20 \mathrm{mg} / \mathrm{kg}$ of $A L A$ compared with control animals that had received similar light dose but no photosensitiser. The value given for each time point represents the mean weight (with 95\% confidence intervals) of all available animals at that particular time point. The minimum number of animals for any time point was three. No animals treated with $A l S_{2} P_{c}$ were allowed to live more than two weeks as their general condition at this time was poor.
Macroscopic changes (bursting pressure study)

At laparotomy 24 hours after thermal injury, a necrotic spot $2 \mathrm{~mm}$ in diameter corresponding to the site of mucosal injury could be seen on the serosal aspect of the stomachs in all four animals. There was no evidence of peritoneal soiling to suggest any perforation. On the mucosal aspect, there was a corresponding area of necrosis. By day 4 after thermal injury, the treated area was covered by inflammatory tissue and omentum on the serosal aspect, which adhered to the site of damage. These changes were more established by day 8 . In both the ALA groups, no visible changes were seen on the serosal aspect in all animals killed at one, four, and eight days after PDT but an area of mucosal necrosis about $10 \mathrm{~mm}$ in diameter could be seen on the luminal aspect in all animals when the stomach was opened out along the lesser curve after bursting measurements. In the $\mathrm{AlS}_{2} \mathrm{Pc}$ group, there were no visible necrotic changes on the serosal aspect of the stomach in all animals killed at day 1 after PDT although the area looked blanched. Oedema was evident, however, on the serosal aspect of the site of treatment in all animals killed at day 4 and by day 8 , there was omental tissue adherent to the treated area in all animals. The omental tissue could be gently peeled off, revealing underlying muscularis and serosal necrosis. This contrasted with the ALA groups in which the lack of omental adhesions to the treated site showed that PDT damage did not extend through to the serosal aspect.

\section{Bursting strength}

Figure 2 shows the bursting pressure of stomachs after treatment in all groups of animals. All stomachs with PDT lesions (with the exception of those with $\mathrm{AlS}_{2} \mathrm{Pc}$ and the omentum peeled off at eight days) perforated at sites away from the lesion - that is, through a linear tear in the antrum. All stomachs with thermal lesions, and the $\mathrm{AlS}_{2} \mathrm{Pc}$ ones with omentum removed at eight days burst through the lesions. Panmural damage in the $\mathrm{AlS}_{2} \mathrm{Pc}$ group was evident in all animals by the eighth day by the presence of inflammatory adhesion of omental tissue to the treatment site. When this tissue was gently peeled off from the treatment site, the burst occurred at this site at a reduced bursting pressure. There were no visible changes on the serosa at the site of PDT damage with ALA photosensitisation even though muscularis necrosis is known to occur with $200 \mathrm{mg} / \mathrm{kg}$ ALA.

\section{Histopathological changes}

In the thermal control group, a localised area of full thickness necrosis with charring at the point of fibre contact was seen one day after injury (Fig 3). This became associated with oedema and acute inflammatory infiltration by day 4 and omental adhesion by day 8 . Coagulative necrosis of the mucosa with widespread karyolysis was seen at day 1 in all PDT groups. Acute inflammatory cells were present in abundance. In the group receiving $\mathrm{AlS}_{2} \mathrm{Pc}$, 
there was sloughing of necrotic mucosa. Smooth muscle necrosis was present, characterised by its loss of staining. The submucosal layer was oedematous with associated vascular congestion and occasional interstitial haemorrhage (Fig 4). By day 8, there was total breakdown of all three layers leaving only the necrotic remnant of the muscularis reinforced by omental tissue adherent to the serosal aspect. New collagen was deposited in the omental tissue adherent to the serosa. By two weeks, there was complete disappearance of necrotic material leaving a full thickness defect bridged only on the serosal aspect by omental tissue, which by this stage stained strongly for collagen fibres. By six weeks, there was complete re-epithelialisation and dense submucosal and muscularis fibrosis (Fig 5). In the two ALA groups, coagulative necrosis of the mucosa was evident after 24 hours. In the group receiving $200 \mathrm{mg} / \mathrm{kg}$ ALA, muscularis damage was shown by vacuolation of some smooth muscle cells. There was less inflammatory cell infiltration compared with the phthalocyanine group. The submucosa
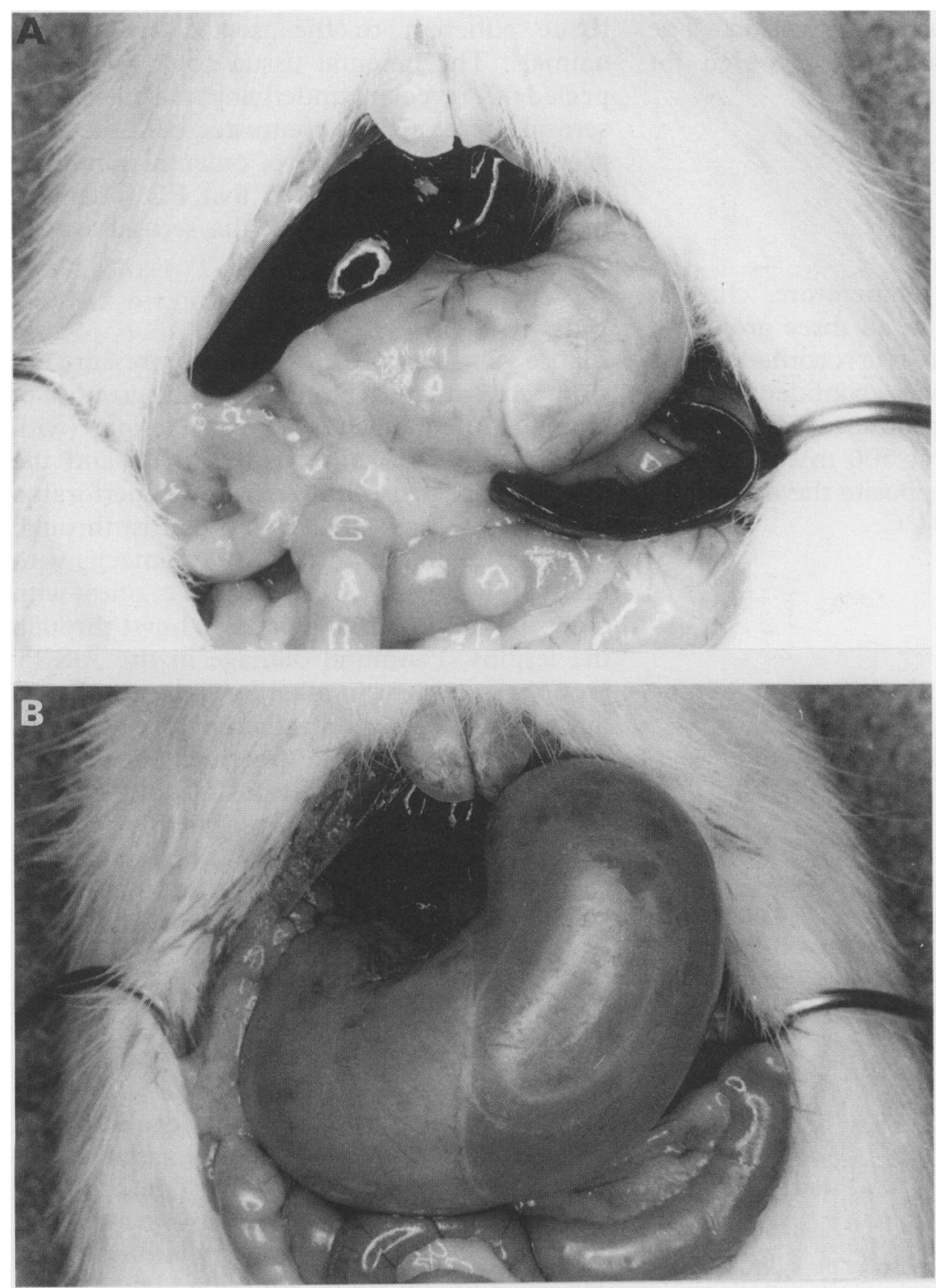

Figure 9: (A) Photograph of a rat stomach two weeks after PDT of the pylorus with 20 $\mathrm{mg} / \mathrm{kg}$ ALA showing an essentially normal stomach. Light dose: $100 \mathrm{~mW} \times 2000$ seconds over an area approximately $1 \mathrm{~cm}^{2}$. (B) Photograph of a rat stomach two weeks after PDT of the pylorus with $2.5 \mathrm{mg} / \mathrm{kg}$ AlS 2 Pc showing gross distension caused by a stenotic pylorus. Light dose: $100 \mathrm{~mW} \times 1000$ seconds over an area approximately $1 \mathrm{~cm}^{2}$. remained intact throughout and there was no omental adhesion. It would seem that mucosa and muscularis necrosis occur without disruption of the tissue architecture and collagen framework, unlike the type of panmural necrosis seen after PDT with $\mathrm{AlS}_{2}$ Pc. New collagen fibres were found deposited in the submucosal layer and serosal aspect by two weeks. In the group receiving $20 \mathrm{mg} / \mathrm{kg}$ ALA, there was only mucosal necrosis and the muscularis mucosae, submucosa, and muscularis propria remained intact (Fig 6). There was little evidence of new collagen deposition during healing at two and six weeks (Fig 7).

\section{Stenosis studies}

Because of the anatomical position of the pylorus, complete shielding of other adjacent organs from the therapeutic light was impossible and some collateral damage was found notably in the liver although this healed without adversely affecting the animals. The appearance at 24 hours after PDT showed consistent circumferential mucosal damage in both PDT groups. Figure 8 shows weight changes of the three groups of animals treated. No effect was seen in the control rats at any time after irradiation and the rats continued to gain weight normally. In the study rats, gross gastric distension was noted at 24 and 48 hours after PDT indicating pyloric obstruction probably caused by oedema. In the ALA group, this distension settled after 72 hours and no distension was seen at one, two, and six weeks (Fig 9A). However, the stomachs in the $\mathrm{AlS}_{2} \mathrm{Pc}$ group remained distended two weeks after PDT (Fig 9B). All animals in the $\mathrm{AlS}_{2}$ Pc group showed severe weight loss and had to be killed at two weeks. Histological changes of the pylorus two weeks after PDT are shown in Fig $10 A$ and $B$, which show an intact submucosal layer with little evidence of fibrosis in the ALA group (Fig 10A) but disruption and fibrosis affecting the submucosal and muscularis layer in the $\mathrm{AlS}_{2} \mathrm{Pc}$ group (Fig 10B).

\section{Discussion}

This study considers some safety aspects of using PDT in the treatment of gastrointestinal dysplasia. Dysplasia is a multicentric condition often with few discernible macroscopic changes to help target any local treatment modality, so PDT has to be administered to the entire affected mucosa. In the oesophagus, it is now technically possible to deliver therapeutic light to large areas of affected mucosa. ${ }^{13}$ The safety of such a treatment approach needs to be assessed, however, particularly with respect to possible change of mechanical strength of the organ immediately after treatment as well as possible scarring in the healing phase, which may lead to stenosis. Perforations and strictures after PDT have been reported and attributed to the lack of tissue selectivity $^{3132}$ although previous work from this centre suggests that this is an unlikely explanation for perforation. ${ }^{23}$ It was more likely that there was a thermal as well as a PDT effect. 


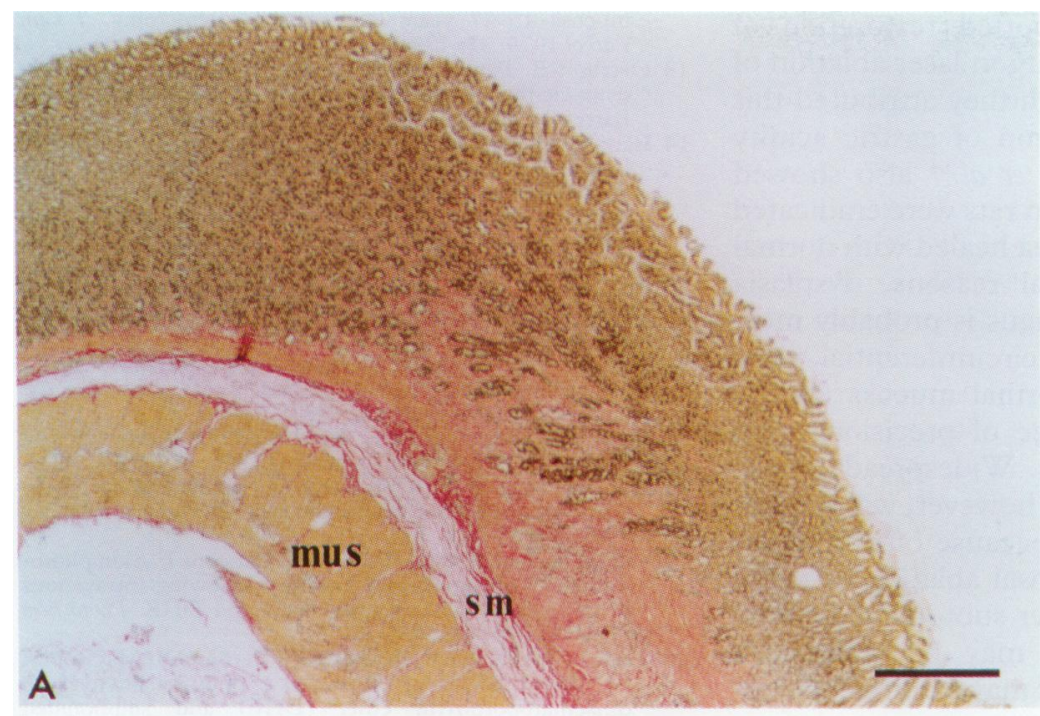

Fig $10 \mathrm{~A}$

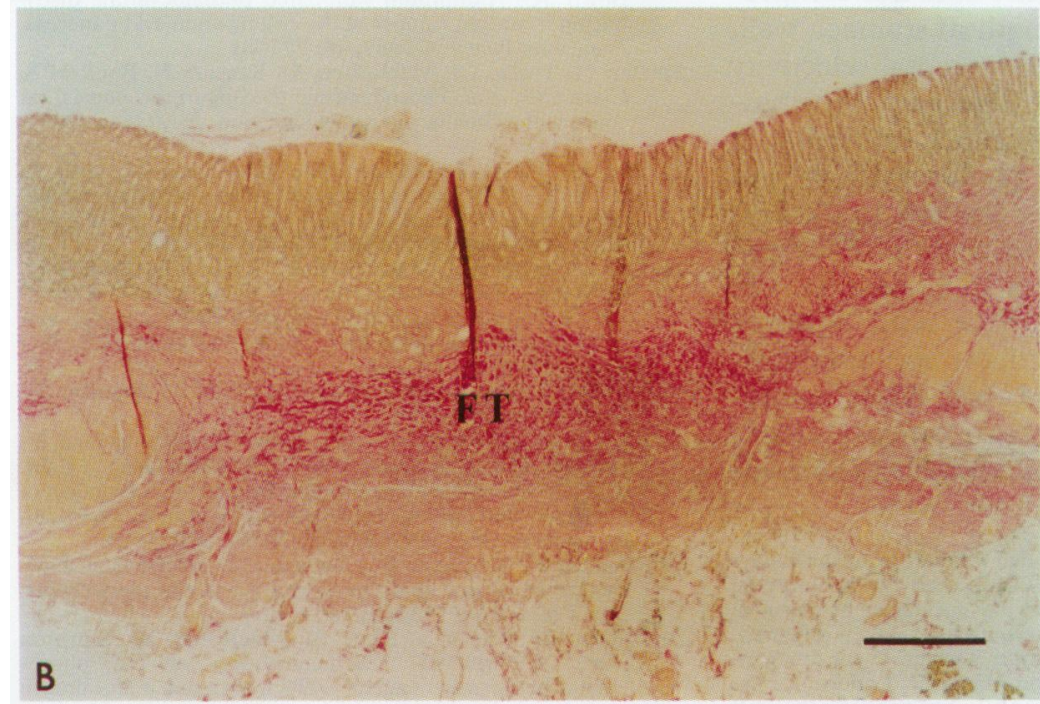

Fig $10 B$

Figure 10: (A) Light micrograph of a longitudinal section of the prepyloric region of a rat stomach (haematoxylin van Gieson stains) two weeks after PDT with $20 \mathrm{mg} / \mathrm{kg} \mathrm{ALA}$. Light dose: $100 \mathrm{~mW} \times 2000$ seconds over an area approximately $1 \mathrm{~cm}^{2}$. The section shows intact submucosal (sm) and muscularis (mus) layers with minimal fibrosis. Scale: the bar in the bottom right corner represents $100 \mu \mathrm{m}$. (B) Light micrograph of a longitudinal section of the prepyloric region of a rat stomach (haematoxylin van Gieson stains) two

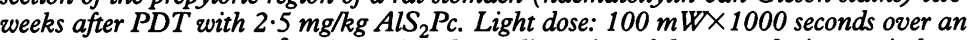
area approximately $1 \mathrm{~cm}^{2}$. The section shows disruption of the muscularis propria layer and formation of fibrous tissue (FT) in the defect. Scale: the bar in the bottom right corner represents $100 \mu \mathrm{m}$. than after thermal necrosis, ${ }^{34}$ but regeneration is not complete. ${ }^{15}$ The mechanism of action of $\mathrm{AlS}_{2} \mathrm{Pc}$, is rather like $\mathrm{HpD}$ and Photofrin. After intravenous administration, highest values were seen in the blood vessel walls and immediate perivascular tissue matrix ${ }^{35}$ of the submucosa. Its photodynamic effect has been shown largely to be on the tissue microvasculature. ${ }^{36} 37$ Barr et al found that although both thermal injury and PDT with $\mathrm{AlS}_{2} \mathrm{Pc}$ produced full thickness damage, mechanical strength was preserved in the second but not the first. ${ }^{22}$

In this study, we found, as Barr et al ${ }^{22}$ did in the colon, that $\mathrm{AlS}_{2} \mathrm{Pc}$ produced full thickness necrosis in the stomach on photoactivation. We have previously shown that the highest value of $\mathrm{AlS}_{2} \mathrm{Pc}$ was found in the submucosa and values in the mucosa and muscularis are approximately the same. ${ }^{24}$ Mucosal and muscularis necrosis was seen on photoactivation as expected. The photochemical effects of $\mathrm{AlS}_{2} \mathrm{Pc}$ on extracellular collagen, however, did not result in it losing its tensile strength in the first few days after PDT. This only happened once the adherent omentum had been removed. One explanation would involve the possible role of gastric acid dissolution of exposed collagen after the necrosed mucosa had sloughed although this would fail to explain the lack of this phenomenon after PDT with ALA. It is also possible that the late collagen destruction can be caused by enzymes released by inflammatory cells in response to localised areas of stomach wall infarction from microvascular collapse caused by PDT with $\mathrm{AlS}_{2} \mathrm{Pc}$.

It has been shown from our previous study that a high ALA dose induces PpIX accumulation in sufficient quantity both in the mucosal and muscularis layers for photodamage to occur. ${ }^{24}$ Thus, besides extensive mucosal necrosis, smooth muscle cell damage was also seen with $200 \mathrm{mg} / \mathrm{kg}$ ALA. Despite this, the general tissue architecture was preserved. With the lower dose of $20 \mathrm{mg} / \mathrm{kg}$ ALA, however, PpIX was only synthesised in sufficient quantity for photodynamic action in the mucosa resulting in a truly selective mucosal necrosis. When this effect was circumferential at the pylorus, there was only transient obstruction, probably because of oedema, with no late stenosis.

The ability to destroy comparatively large areas of mucosa without weakening the organ or causing stenosis should open the way to photodynamic ablation of diffuse dysplastic mucosa in the gastrointestinal tract such as those seen in Barrett's oesophagus, and possibly also with atrophic gastritis, the remnant left after partial gastrectomy and the dysplastic mucosa of chronic ulcerative colitis and familial polyposis. The other crucial unknown is how necrosed dysplastic mucosa heals. If there is regeneration of dysplastic mucosa, then nothing has been achieved, but if healing is by regeneration of normal mucosa, this could represent a significant advance in treatment for these patients. Few data are available on this, although Overholt et al ${ }^{13}$ reported regeneration with non-dysplastic epithelium after PDT for early adenocarcinoma with dysplasia in Barrett's oesophagus effect mainly by causing vascular collapse of the submucosal stroma. It is possible that primary damage of this layer after PDT is followed by fibrosis. Another possibility is fibrosis subsequent to muscle necrosis. Skeletal muscle regenerates better after PDT 
and Berenson et al reported restoration of squamous mucosa after argon laser ablation of Barrett's mucosa although they attributed this restoration to the abolition of gastric acidity with omeprazole. ${ }^{38}$ Barr et al ${ }^{14}$ also showed that when colon cancers in rats were eradicated by PDT, the necrosed area healed with normal mucosa. For geometrical reasons, dysplasia seen in Barrett's oesophagus is probably most amenable to PDT as circumferential light illumination of the abnormal mucosa can be carried out with a degree of precision using cylindrical light diffusers. Widespread diffuse dysplasia in the stomach, however, will present a therapeutic challenge because of difficulties with light delivery. Mucosal ablation of rectal stumps such as those after subtotal colectomy for colitis or polyposis may be technically easier and such treatment may facilitate preservation of sphincters for future use.

In conclusion, we have shown that PDT using both $\mathrm{AlS}_{2} \mathrm{Pc}$ and ALA does not compromise the mechanical strength of stomach wall, although ALA offers better mucosal selectivity with less risk of stenosis. The photosensitisation kinetics of ALA also reduce morbidity in terms of prolonged skin photosensitivity and should make PDT more acceptable to patients and more popular with clinicians. Recently, preliminary clinical trials of PDT with ALA in the gastrointestinal tract have been reported with no significant side effects and complications to the patients. ${ }^{39}$ Using ALA, photodynamic ablation of dysplastic mucosa should be explored as a possible alternative to conventional excisional surgery.

Dr Loh and Dr Krasner acknowledge funding from the Lasers for Life Trust. Professor Bown is supported by the Imperial Cancer Research Fund. Dr Loh was also supported by a project grant from the Association for International Cancer Research. We are grateful to Professor D Phillip's group at the Imperial College of Science, Technology and Medicine, London for the supply of phthalocyanine. We would also like to thank the staff of the Histopathology Unit of the Imperial Cancer Research Fund for processing of histological specimens.

1 Schmidt HG, Riddell RH, Walther B, Skinner DB, Riemann JF. Dysplasia in Barrett's esophagus. $\mathcal{f}$ Cancer Res Clin Oncol 1985; 110: 145-52.

2 Miros M, Kerlin P, Walker N. Only patients with dysplasia progressed to adenocarcinoma in Barrett's oesophagus. Gut 1991; 32: 1441-6.

3 Hameeteman W, Tytgat GNJ, Houthoff HJ, Van Den Tweel JG. Barrett's esophagus: development of dysplasia Tastroenterology 1989; 96: and adeno 1246 .

4 Ming SC, Baitai A, Correa P, Elster K, Javi OH, Munoz N, et al. Gastric dysplasia. Significance and pathological criet al. Gastric dysplasia. Significan

5 Morson BC, Sobin LH, Grundmann E, Johansen A Nagayo T, Serk-Hanssen A. Precancerous conditions and epithelial dysplasia in the stomach. $\mathcal{F}$ Clin Pathol 1980; 33 711-21.

6 Offerhaus GJA, Stadt JVD, Huibregtse K, Tytgat GNJ. Endoscopic screening for malignancy in the gastric remnant: the clinical significance of dysplasia in the gastric mucosa. F Clin Pathol 1984; 37: 748-54.

7 Correa P, Haenszel W, Cuello C, Zavala D, Fontham E, Zarama G, et al. Gastric precancerous process in a high risk population: cohort follow up. Cancer Res 1990; 50: risk populat $4737-40$.

8 Farrands PA, Blake JR, Ansell ID, Cotton RE, Hardcastle ID. Endoscopic review of patients who have had gastric surgery. $B M 7$ 1983; 286: 755-8.

9 Rusch VW, Levine DS, Haggitt R, Reid BJ. The management of high grade dysplasia and early cancer in Barrett's oesophagus: a multidisciplinary problem. Cancer 1994 74: 1225-9.

10 Altorki NK, Sunagawa M, Little AG, Skinner DB. Highgrade dysplasia in the cloumnar-lined esophagus. $A m \mathcal{F}$ Surg 1991; 161: 97-100.

11 Rice TW, Falk GW, Achkar E, Petras RE. Surgical management of high-grade dysplasia in Barrett's esophagus. Am $\mathcal{f}$ Gastroenterol 1993; 88: 1832-6.

12 Savage A, Jones S. Histological appearances of the gastric mucosa 15-27 years after partial gastrectomy. $\mathcal{f}$ Clin Pathol 1979; 32: 179-86.

13 Overholt B, Panjehpour M, Tefftellar E, Rose M. Photodynamic therapy for treatment of early adenocarcinoma in Barrett's esophagus. Gastrointest Endosc 1993; 39: 73-6.

14 Barr H, Chatlani P, Tralau CJ, MacRobert AJ, Boulos PB, Bown SG. Local eradication of rat colon cancer with photodynamic therapy: correlation of distribution of photosensitiser with biological effects in normal and photosensitiser with biological effect

15 Pope AJ, Bown SG. The morphological and functional changes in rat bladder following photodynamic therapy with phthalocyanine photosensitization. F Urol 1991; 145: 1064-70.

16 Dougherty TJ. Photodynamic therapy. In: Jori G, Perria C, eds. Photodynamic therapy of tumors and other diseases. Padova: Libreria Progetto, 1985: 268-79.

17 Byrne CJ, Marshallsay LV, Ward AD. The composition of Photofrin. F Photochem Photobiol B 1990; 6: 13-27.

18 Ho Y-K, Missert JR, Dougherty TJ. Activity and physicochemical properties of Photofrin $\otimes$. Photochem Photobiol 1991; 54: 83-7.

19 Razum N, Balchum OJ, Profio AE, Carstens F. Skin photosensitivity: duration and intensity following intravenous sensitivity: duration and intensity following intravenous Photobiol 1987; 46: 925-8.

20 Tralau CJ, Young AR, Walker NPJ, Vernon DI, MacRobert $\mathrm{AJ}$, Brown SB, et al. Mouse skin photosensitivity with dihaematoporphyrin ether (DHE) and sulphonated phthalocyanine (AlSPc): a comparative study. Photochem Photobiol 1989; 49: 305-12.

21 Tralau CJ, Barr H, Sandeman DR, Barton T, Lewin MR, Bown SG. Aluminium sulfonated phthalocyanine distribution in rodent tumors of the colon, brain and pancreas. Photochem Photobiol 1987; 46: 777-81.

22 Barr H, Tralau CJ, MacRobert AJ, Krasner N, Boulos PB, Clark CG, et al. Photodynamic therapy in the normal rat Clark CG, et al. Photodynamic therapy in the normal rat 56: $111-8$.

23 Barr H, Tralau CJ, Boulos PB, MacRobert AJ, Tilly R, Bown SG. The contrasting mechanisms of colonic collagen damage between photodynamic therapy and therma injury. Photochem Photobiol 1987; 46: 795-800.

24 Loh CS, Bedwell J, MacRobert AJ, Krasner N, Phillips D, Bown SG. Photodynamic therapy of the normal rat stomach: a comparative study between disulphonated alu-
minium phthalocyanine and 5 -aminolaevulinic acid. $B r f$ Cancer 1992; 66: 452-62.

25 Marriott J. Regulation of prophyrin synthesis. Biochem Soc Symp 1968; 28: 61-74.

26 Rimington C. Prophyrin and haem biosynthesis and its control. Acta Med Scand 1966; 179 (suppl 445): 11-24. 27 Malik Z, Djaldetti M. 5-aminolevulinic acid stimulation of porphyrin and hemoglobin synthesis by uninduced Friend erythroleukemic cells. Cell Differ 1979; 8: 223-33.

28 Sima AAF, Kennedy JC, Balkeslee D, Robertson DM Experimental porphyric neuropathy: a preliminary report. Can F Neurol Sci 1981; 9: 105-14.

29 Bishop SM, Beeby A, Khoo BJ, MacRobert AJ, Simpson MSC, Phillips D. Characterisation of the photochemotherapeutic agent disulphonated aluminium phthalocyanine and its high performance liquid chromatographic separated components. $\mathcal{f}$ Chromatogr 1993; 644: 345-50.

30 Hawley PR. The aetiology of colonic anastomotic leaks with specific reference to the role of collagenase [MS Thesis]. specific reference to the role of collag
London: University of London, 1970.

31 Monnier Ph, Savary M, Fontolliet Ch, Wagnieres G, Chatelain A, Cornaz P, et al. Photodetection and photodynamic therapy of 'early' squamous cell carcinomas of the pharynx, oesophagus and tracheo-bronchial tree Lasers in Medical Science 1990; 5: 149-69.

32 Patrice T, Foultier MT, Yactayo S, Douet MC, Maloisel F Le Bodic L. Endoscopic photodynamic therapy with haematoporphyrin derivative in gastroenterology. Ұ Photochem Photobiol B 1989; 6: 157-65.

33 Star WM, Marijnissen HPA, Van Den Berg-Blok AE, Versteeg JAC, Franken KAP, Reinholds HS. Destruction of rat mammary tumor and normal tissue microcirculation by hematoporphyrin derivative photoirradiation tion by hematoporphyrin derivative photoirradiation observed in vivo in sandwiched

34 Chevretton EB, Berenbaum MC, Bonnett R. The effect of photodynamic therapy on normal skeletal muscle in an animal model. Lasers in Medical Science 1992; 7: 103-10.

35 Chatlani PT, Bedwell J, MacRobert AJ, Barr H, Boulos PB Krasner N, et al. Comparison of di- and tetra-sulphonated aluminium phthalocyanines in normal rat colon Photochem Photobiol 1991; 53: 745-51.

36 Nelson JS, Liaw LH, Orenstein A, Roberts WG, Berns MW. Mechanism of tumor destruction following photodynamic therapy with hematoporphyrin derivative, chlorin, and phthalocyanine. $\mathcal{F}$ Natl Cancer Inst 1988; 80: 1599-605.

37 Milanesi C, Biolo $R$, Reddi E, Jori G. Ultrastructural studies on the mechanism of the photodynamic therapy of studies on the mechanism of the photodynamic

38 Berenson MM, Johnson TD, Markowitz NR, Buchi KN, Samowitz WS. Restoration of squamous mucosa after ablation of Barrett's esophagus epithelium. Gastroenterology 1993; 104: 1686-91.

39 Regula J, MacRobert AJ, Gorchein A, Buonaccorsi GA Thorpe SM, Spencer GM, et al. Photodynamic therapy using 5-aminolaevulinic acid in colonic and oesophagea tumours - a pilot study. Gut 1995; 36: 67-75. 